\title{
Impact of Stress on Students Academic Performance at Secondary School Level at District Vehari
}

\author{
Muhammad Saqib \\ University of Agriculture Faisalabad Sub-Campus Burewala-Vehari \\ Chak No. 43/W.B 6Lot Vehari, Punjab, Pakistan
}

Tel: 92-300-7738227Ｅ-mail: joiya.saqib@gmail.com

Kaleem Ur Rehman

Lecturer UOG Narowal Campus

Visitor Lecturer UAF Sub-Campus Burewala-Vehari

Received: October 22, 2017 Accepted: January 30, 2018 Published: February 13, 2018

doi:10.5296/ijld.v8i1.12063

URL: https://doi.org/10.5296/v8i1.12063

\begin{abstract}
The title of the existing topic is "Impact of stress on student's academic performance at secondary school level". The important motives of this study are to explore the stress impact on the students' academic performance. Stress has a key role in student's academic performance. This study was to focus on the negative impact on the student's academic performance. The purposes of the study were to investigate; firstly, the type of stress linked with student's performance; secondly, to evaluate the impact of stress on the academic performances of students; and thirdly, differentiate the impacts of stress on the academic performances of both gender students. To achieve the above-mentioned objectives of the study, the researcher can suggest a reasonable solution for the impact of stress on student's academic performance. The data collected for this topic, has been gathered from all the secondary schools in District Vehari. In this study the researcher was taken a sample of $(n=10)$ secondary schools from each Tehsil of District Vehari. The researcher was further divided $(n=10)$ secondary schools into two groups $(n=5)$ males and $(n=5)$ female secondary schools. The researcher was taken $(n=15)$ students from each secondary school selected as sample. The researcher was used simple random sampling technique for data collection. Five points Likert-scale used in this research.
\end{abstract}


99\% respondents are responding about the factor of stress impact on their academic performance. After collecting data, it was analyzed by using Statistical Package for Social Sciences (SPSS) version 20. The tool (questionnaire) used for the collection data was 0.850 Cronbach alpha. In this study, different tests were applied as to factor analysis and regression. Generally, the major findings of study divulged that there are significant impacts of stress on student's academic performance. This study concluded that major factors of stress among the students are teacher and parents.

Keywords: Impact of stress, factor of stress on male and female

\section{Introduction}

Stress is a main source of problems being faced by the students during their academic carrier when they are struggling to get the academic achievements for their future life. Academic pressure is one of the factors that cause failure among the students. Stress is the response of mental and action through hormonal signaling, the perception of danger sets off an automatic response system, known as the fight or flight response. Commonly stress refers to two things, the psychological perception of pressure, on the one hand, and the body's response to it, on the other, which involves multiple systems, from breakdown to muscles to memory. Stress is a lot of expectation from self. Stress is the feeling of strain and pressure. Stress is a threating feeling (Cohen et al., 1997).

Psychological stress occurs when an individual perceives that environmental demands duty or exceed his or her adaptive capacity. Stress generate psychological disorders that may arise as downstream (Jex, 1998). Many different things can cause physical stress, such as fear of something dangerous or emotional, such as concern about your family or work and a poor outcome in the study. This is a reaction to things around you that cause stress (Manuel et al., 2003). It is important to note that stress can have both negative and positive impact on students. Most psychologists assert that moderate stress motives individuals to achieve and fuels creativity, although stress may hinder individuals from performance on the difficult task. (Nelson \& Simmons, 2003). Stress impact on the emotional and physical behavior of persons. It is perceived as events or situations that reason individuals to feel tension, pressure, or negative emotions (Bernstein et al., 2008).

Academic performance is the educational aim that is achieved by a student, teacher or institution achieves over a specific time. The academic performance of students heavily depends upon the parental involvement in their academic activities to attain the higher level of quality in academic success. The students are quite emotional especially females. They are take stress in everything at school level. A lot of factor that influence in their study like present pressure, teacher's attitude towards their study, home strictness, future and job tensions (Hussain et al., 2012). 


\subsection{Objective}

Following will be objective of study;

To identify the stress factors which affect the students' performance.

$>$ To differentiate the impacts of stress on the academic performances of male and female students.

\section{Review of Literature}

The study of stress hypothesized stress as the interaction between the three fundamentals perceived as the perception of coping ability, and the perception of the importance of being able to cope with its demand. Different from many previous definitions of stress, this formulation clearly integrates the transactional process that is believed to be central to current theories of academic assessment. Stress is simply seen as a mismatch between demand and capacity on the difference, the insight of these two elements, and the most important the desire or the motivation that one feels to answer all the requests are at the heart of the construction (Aikens et al.,1992)

Gunnar (1998), defined the explanation of academic stress is the anxiety and stress that comes from schooling and education. There is regularly a lot of compressions that comes along with following a degree and one's education. There is studying homework, tests, labs, reading, and quizzes. There is the stress of doing all of the work, balancing the time and finding time for extra-curricular activities. Academic stress is particularly hard on school students who are often living away from home for the first time. Its study show that teachers expect work to be completed on time. Students may miscalculate the amount of time it takes to complete reading and writing tasks, to print out replicas of their work. Stress and its displays, such as stress, depression, and tension, have always been seen as a common problem among people in different businesses and occupations. In the last few times, the alarm has previously been motivated by the proliferation of books, research reports, popular articles and the growing number of organized workshops, aiming to teach people how to handle with this individuality.

Researchers are randomly in their actions on this subject, in some cases associating and unique in others. While one can say that each stress factor has immediate effects, each can also have side effects. For example, time pressure limits the time available for the success of a particular task. This limit is a physical limit that does not require psychological explanation to sympathize with its immediate effects on achieving performance. This limitation, however, often causes an emotional reaction, for example nervousness that has side effects or indirect effects on success. Given the effort of unravelling these two extensions and scarcity in which this was done in the main literature (Trockel et al., 2000).

While Baumeister and Exline (2000) description of stress provides a complex concept of stress, it says little about how stress affects human academic and other performance. There is important variation between researchers about the direct and indirect properties of several suppose different factors which have to create stress in any situation. Direct stress special effects are those experienced by the mission capacity alone unrelatedly of any psychological 
stress that may also be generated. According to Rees and Redfern (2000) indirect stress effects are developed from psychological stressors related to task load requirements. There is an acceptable line that is mutual with these two, and they can sometimes not be distinguished. This fact made their departure and measurement extremely difficult.

Ashcraft and Kirk (2001) shows that students with high stress tend to be slower and more considerate in their action of various aspects of specialized purposes. For example, these persons give the impression to have particular difficulty with the carryover role. With the connection between this function and work memory, scientists have imagined that the extra stress present in highly nervous subjects probably withdraws resources that can then be used in work memory for activation and rehearsal as needed for the carrying operation. Although it has been challenged that high stress individuals may simply be less qualified to be subject to inability and not stress different studies have given an indication that professional competence is not satisfactory to explain the phenomena. Instead, it has directed our sympathetic towards resource reduction models. Specifically, it has been said that concern and disturbing thoughts compete for the limited pool of resources.

This study investigated the effects of academic stress on the performance of different cognitive tasks, predicted that matte stress would interfere with work memory, leading to a breakdown in mathematical and related performance. Specifically, these authors measure the degree to which subjects were stressed using a self-reporting index shortly followed by a performance assessment of two measurements of the work environment reading team and calculation group. Their results suggest that people who score high on measurements or tensions tend to perform worse on work memory measurements. While this was the case in both ways, it was not necessarily limited to just computational tasks, high stress subjects were more likely to demonstrate failure in computational results than listening outcomes (Slaven,and Windle. 1999).

According to Bandura (2001) it is possible to learn an assignment and yet perform poorly in it. Academic success impact on the students because when you get success in their academic achievements then students feel relax and full confidence in their study. Other factors, other than the learning process and suffering have the potential of influencing academic performance on tasks. According to Tepas and Price (2001), stress can be viewed as, an agent, circumstance, situation, or variable that disturbs the normal functioning of the individual. Stress is also understood as an effect that is the troubled state itself. This branching of meaning is doubtfully the most fundamental source of the confusion surrounding the stress concept. The stress reaction can only arise if the person perceives the circumstance or assignments as a stressor. Various demands or stimuli may be referred to as a stressor and may be emotionally or psychological in nature. Individuals perceive events differently, and the same event may cause different stress responses from different people.

Stress is typically defined in two categories, short-term and long term. Stress is experienced for a short period of time and is usually caused by a traumatic event. Acute stress is sometimes considered as beneficial and can create motivation. Its study further provides an example where a student is approaching a deadline, which is causing the student stress. The stress that is 
caused due to this deadline is considered good because it is temporary and hence helps the student to focus and complete their task before the given time. A student being stressed during an examination is a very common depiction. Some of the symptoms by which stress is identified include a headache, shortness of breath, and dizziness. A certain amount of acute stress can be seen among everyone and student pilots are no exception. There have been studies that show that students who have a just started their flying lessons suffer from more acute stress than pilots who have a commercial pilot license. Other reasons that can cause acute stress among pilots have delayed flights, long duty schedules, and in-flight emergencies. Situations such as delayed flights not only cause stress but also affect the pilot's performance and can result in a pilot error (Seki et al., 2002).

Academic performance is the educational aim that is achieved by a student, teacher or institution achieves over a specific time. Academic performance depends on the school, teacher and staff management. This is measured either by examinations or continuous assessments and the goal may differ from an individual or institution to another. Especially teachers play the main role in the academic achievement. Academic achievement is a period used in school when a student does well in academic's performance. Academic performance is the successes which demand from parent's family and friends. They achieve or do well in an area of the school and do well in their studies. Academic performance is not only degree it is the identification of any students. All the successes in every field of life depend on the academic achievement. The academic performance of students seriously depends upon the parental involvement in their academic activities and to achieving the advanced level of excellence in academic success (Barnard, 2004).

Academic achievement as demonstrated using scores on tests has the end of the years been used to determine the competence of a student their classroom. The total mark in the course is a measure of a student's average academic performance across the courses being offered in any given class. This research points out it incorporates all the learning outcomes expected of a student in his/her courses. The outcomes in subjects or mark is a more generally used measure of academic success. Thus allows it to be compared with other studies where measurement of academic achievement is one of the study variables. The output of any course of study reflects the success in academic performance. Learning process depends on the learning and experiencing for academic achievement (McKenzie et al., 2004).

Stress question has become tough question many researchers try to find out a prominent answer of this question It's a question that has beguiled many comprehensive researchers of this era. The term itself is amorphous and sustains the difficulty in discerning its meaning. Definitions of stress range from metallurgical strain to one's emotional wit's end. Stress, on the other hand, is described as a stress that a person suffers for a long time due to a situation that has not been resolved. This is sometimes seen in students, but not as often as acute stress. Stress experienced over a long term can effect human health and create conditions such as heart disease or stomach ulcers (Dahlin et al., 2005).

This study to suggest that the term's versatility its range of application, is its undoing as a useful scientific term or concept, and they are not alone in this assertion. There appear to be a 


\section{Al Macrothink}

International Journal of Learning and Development

ISSN 2164-4063 2018, Vol. 8, No. 1

lot of definitions about the stress as there are stress researchers. Stress effects on the different situation to the students in their study. Because students have different capacity to face the tough situation in their study. The environmental conditions, one's reaction to the event, and the emotional response to the demand are the major components of stress (Fliege et al., 2005).

\section{Research Methodology}

The study was descriptive in nature. Descriptive research is concerned with how what or what exists to some preceding event that has influenced or affected a present condition or event. In this study, data was collected through questionnaires by using survey method in order to measure and describe the general features of the aspect. This study was delimited to District Vehari. The material of studies was collected from all the secondary schools of District Vehari (Burewala, Mailsi and Vehari). From this population the researcher was taken a sample of $(\mathrm{n}=10)$ secondary schools from each tehsil of district Vehari. The researcher was further divide $(n=10)$ secondary schools into two group $(n=5)$ males and $(n=5)$ female secondary schools. The researcher was taken $(n=15)$ students from each secondary school selected as sample. The researcher was used simple random sampling technique for data collection.

Table 1. Distribution of the sample (Combined)

\begin{tabular}{lllllll}
\hline Type of school & Gender & Class & Vehari & Burewala & Mailsi & Total \\
\hline Public & Male & $10^{\text {th }}$ & 75 & 75 & 75 & 225 \\
& Female & $10^{\text {th }}$ & 75 & 75 & 75 & 225 \\
\hline Total & & 150 & 150 & 150 & $\mathbf{4 5 0}$ \\
\hline
\end{tabular}

After an extensive review of the related literature, a questionnaire was designed to investigate the impact of stress on students' academic performance at secondary level. Part-I contains demographic information such as gender. Part-II consists of 52 questions. Students' academic stress questionnaire (SASQ) was prepared by the researcher and it was for collecting data about independent variable. For close ended questions, five-point Likert scale (from strongly disagree to strongly agree). The value of Cronbach alpha was 0.850 , which shows high level of reliability of the scale (questionnaire). Thereafter, data was analyzed. Statistical package for social sciences was used for analysis of data and to find out the frequencies, Percentage and Mean score value. The result of paired Regression was tested on the basis of statistically significance level of 0.05 . 


\section{Research Findings}

Table 2. t-test results comparing the impact of stress on male and female students

\begin{tabular}{llllll}
\hline Group Statistics & & & & & \\
\hline Statements & Gender & N & Mean & T & P value \\
\hline Teacher Stress & Male & 225 & 4.600 & -0.267 & 0.789 \\
& Female & 225 & 4.607 & & \\
\hline Academic Result & Male & 225 & 4.573 & 0.928 & 0.353 \\
& Female & 225 & 4.554 & & \\
\hline Family Pressure & Male & 225 & 4.551 & 0.502 & 0.615 \\
& Female & 225 & 4.533 & & \\
\hline Future & Male & 225 & 4.412 & -1.612 & 0.107 \\
Stress & Female & 225 & 4.490 & & \\
\hline
\end{tabular}

Table demonstrates that independent sample t-test was running out gender wise impact of stress on student's academic performance at secondary level. The result of above table shows that significant noticed between male and female students on impact of stress. The teacher stress $t$-value is -0.267 and $p$-value is 0.789 . The academic result $t$-value is 0.928 and $p$-value is 0.353 . The home strictness $t$-value is -0.116 and $p$-value is 0.907 . The family pressure $t$-value is 0.502 and $p$-value is 0.615 . The Future stress t-value is -1.612 and $p$-value is 0.107 . The above mentioned result shows that there is no impact of stress between male and female students. This result calculated that same factors effect on student's academic performance.

Table 3. Impact of stress on student's academic performance

\begin{tabular}{llllllll}
\hline Dependent Variable & Independent Variable & B & t & Sig & F & R & R Square \\
\hline Students Performance & Stress & .796 & 7.445 & .000 & 773.75 & .796 & .633 \\
\hline
\end{tabular}

Above mention table elaborates that impact of stress on student's academic performance. The $(\mathrm{F}=773.75, \mathrm{p}=.000)$ value is significant. The value of independent variables represents that one unit increase in independent variable will increase $(B=0.796)$ in dependent variable. The value of $(t=7.445, p=.000)$ is also significant.

\section{Conclusions}

On the basis of data collected, following conclusion was made: 
Most of the teachers give punishment to the students in a classroom on their weakness and shortcomings. Majority of teachers do not provide feedback to the students properly, which may be helpful to overwhelm their weakness and shortcomings. The teachers should give encouragement to the students and also to extend personal attention in the classroom. Most of the teachers often fail to clarify the objective of the lesson during class which creates a great hindrance to understand the objectives and the same later on put the student under stress at the end or in mid-terms exams. They do not have a methodology to teach that's major fault to create stress to students. The majority of teachers highlight wrong answers and also give number of exercise and tests to the students; but, they do not explain them on the paper and during the lecture in class room. Most of the teachers do not understand teaching content properly during their lectures. The teachers do not listen the ideas of students emerged during the lectures that caused bad impact on their learning abilities. Most of the students raised volume regarding gap of communication among teachers and students and by removing the communication gap, a healthy environment can be developed for a conversation with all students in the classroom. The teachers show their socio economic status that effects on the students learning. Most of the students complain that they have no opportunity to meet their teacher in free time for learning purposes and to understand the true meanings of the lectures delivered. Most of the students replied that they feel proud that their teachers treat them equally in the classroom and out of the classroom.

\section{Recommendations}

The current research was conducted to identify the impact of stress on student's academic performance at secondary school level and removal thereof among them is biggest price of success. Stress scores equal effect among male and female students. Findings of this study show that the teacher can plays a vital role in removing student's academic stress. To minimize the effect of students' academic performance in secondary schools, all concerned have to work on the issue seriously. The teachers should provide good teaching methodologies to enhance the learning skills and ideas for students. Seminars and workshops should be convened so that traditional as well as modern ways of teaching be explored. The teachers should not put the students under pressure for tuition. The teacher should provide proper guidelines about exams and tests. Parent and other family members have key role in student academic performance. Parents should provide all necessities of the school and also to keep check and balance of their children's educational and non-educational activities. The possible gap between teachers and students may try to cover by calling the Parents' meeting regularly especially once in a month. Some period must be set out in which teachers and students may have non-educational activities in order to cover the gap as well as to know that the teachers are also their well-wishers. In addition, parents should help their children for homework. At home, parents should check the schoolwork of their children to give an impression to sort-out the difficulties being faced by them during learning process. Qualified, experienced, well-behaved and skilled teachers are the main source to guarantee the input of quality of education. The students must aware of the relevant topics while taking examinations and tests actively and efficiently. The parents and teachers should play an important role in a student's life for setting a realistic role for future practical as well as domestic life in order to be a successful and well trained 
personality.

\section{References}

Aikens, J. E., Wallender, J. L., Bell, D. S., \& Cole, J. A. (1992). Daily stress variability, learned resourcefulness, regimen adherence, and metabolic control in Type I diabetes mellitus: Evaluation of a path model. Journal of Counseling and clinical psychology, 60(1), 113-118. https://doi.org/10.1037/0022-006X.60.1.113

Ashcraft, M. H., \& Kirk, E. P. (2001). The relationships among working memory, math anxiety, and performance. Journal of experimental psychology: General, 130(2), 224. https://doi.org/10.1037/0096-3445.130.2.224

Bandura, A. (2001). Social cognitive theory: An agentic perspective. Annual review of psychology, 52, 1-2. https://doi.org/10.1146/annurev.psych.52.1.1

Barnard, W. M. (2004). Parent involvement in secondary schools and educational attainment. Children and Youth Services, 26, 39-42. https://doi.org/10.1016/j.childyouth.2003.11.002

Baumeister, R. \& J. Exline. (2000). Self-control, morality, and human strength. Journal of Social and Clinical Psychology, 19(1), 29-42. https://doi.org/10.1521/jscp.2000.19.1.29

Bernstein, D. A., Penner, L. A., Stewart, A. C., \& Roy, E. J. (2008). Psychology. Houghton Mifflin Company Boston New York.

Cohen, S., Kessler, R.. C., \& Gordon, L. U. (1997). Measuring stress, A guide for health and social scientists. Oxford University Press on Demand.

Dahlin, M., Joneborg, N., \& Runeson, B. (2005). Stress and depression among medical students: A cross - sectional study. Medical education, 39(6), 594-604. https://doi.org/10.1111/j.1365-2929.2005.02176.x

Fliege, H., Rose, M., Arck, P., Walter, O., Kocalevent, R., Weber, C., \& Klapp. B. F. (2005). The perceived stress questionnaire reconsidered: validation and reference values from different clinical and healthy adult samples. Psychosomatic Medicine, 67(1), 78-88. https://doi.org/10.1097/01.psy.0000151491.80178.78

Gunnar, M. R. (1998). Quality of early care and buffering of neuroendocrine stress reactions. Potential effects on the developing human brain. Preventive medicine, 27(2), 208-211. https://doi.org/10.1006/pmed.1998.0276

Hussain, I., Ahmad, M., Ahmad, S., Suleman, Q., Din, M. Q., \& Khalid, N. (2012). A Study to Investigate the Availability of Educational Facilities at Secondary School Level in District Karak. India. 234-25.

Jex, S. M. (1998). Stress and job performance Theory, research, and implications for managerial practice. Sage Publications Ltd.

Manuel, J., Naughton, M. J., Balkrishnan, R., Smith, B. P., \& Koman. L. A. (2003). Stress and adaptation in mothers of children with cerebral palsy. Journal of Pediatric Psychology, 


\section{INacrothink}

International Journal of Learning and Development

ISSN 2164-4063 2018, Vol. 8, No. 1

28(3), 199-201. https://doi.org/10.1093/jpepsy/jsg007

McKenzie, K., Gow, K., \& Schweitzer, R. (2004). Exploring first year academic Achievement through structural equation modeling. Higher Education Research and Development, 23(1), 95-102. https://doi.org/10.1080/0729436032000168513

Nelson, D. L., \& Simmons, B. L. (2003). Health psychology and work stress. A more positive approach. Handbook of occupational health psychology, 2, 100-103.

Seki, M., Narusaka, M., Ishida, J., Nanjo, T., Fujita, M., Oono, Y., \& Satou, M. (2002). Monitoring the expression profiles of 7000 Arabidopsis genes under drought, cold and high salinity stresses using a full - length cDNA microarray. The Plant Journal, 31(3), 279-292. https://doi.org/10.1046/j.1365-313X.2002.01359.x

Slaven, G. M., \& Windle, C. M. (1999). Cognitive performance over 7 days in a distressed submarine. Aviation, space, and environmental medicine, 70(6), 604-608.

Tepas, D. I., \& Price, J. M. (2001). What is stress and what is fatigue. Stress, workload, and fatigue. Mahwah, NJ: L. Erlbaum.

Trockel, M. T., Barnes, M. D., \& Egget, D. L. (2000). Health related variables and academic performance among first-year college students: Implications for sleep and other behaviors. Journal of American College Health, 49(3), 125-131. https://doi.org/10.1080/07448480009596294

\section{Copyright Disclaimer}

Copyright for this article is retained by the author(s), with first publication rights granted to the journal.

This is an open-access article distributed under the terms and conditions of the Creative Commons Attribution license (http://creativecommons.org/licenses/by/4.0/). 